\title{
LEADERSHIP APPROACH IN RELATION TO LEVEL OF CONSCIOUSNESS: A CORRELATIONAL ANALYSIS
}

\author{
Vaibhav Chauhan, Sadhna Sharma and \\ $\mathrm{Nandita} \mathrm{Sats}$ angee
}

The present empirical study was designed to explore the relationship between the leadership approach of teacher trainees and their level of consciousness. A descriptive survey was conducted on 100 teacher trainees (both male $\mathcal{E}$ female in the ratio of 1:1). The level of consciousness of teacher trainees was assessed using Consciousness Quotient Inventory (CQ-i) by Brazdau (2011). To assess the leadership approach Multifactor Leadership Questionnaire (MLQ-6S) by Bass and Avolio (1992) was used. The relationship between scores on seven leadership factors (comprising three leadership approaches) and the level of consciousness was studied using Pearson's product moment correlation. Results indicate a significant positive correlation to a varying degree between consciousness and three leadership approaches .

KEYWORDS: Leadership Approach, Consciousness, Transformational
Leadership

\section{INTRODUCTION}

Almost every kind of change be it globalization, technological advancement, social, political or economic transformation, effects a nation's education system directly or indirectly. Education system has to respond to such shifts from time to time. For this, teachers have a prominent role to play because the quality of an educational system cannot exceed the quality of its teachers (Barber \& Mourshed, 2010). The central place the teacher leadership occupies

\footnotetext{
Vaibhav Chauhan $\square$

Research Scholar, Faculty of Education, Dayalbagh Educational Institute. Agra (U.P.)

E-mail:vaibhav.vps.chauhan@gmail.com

Sadhna Sharma

Research Scholar, Faculty of Education, Dayalbagh Educational Institute. Agra (U.P.)

E-mail:khushboolavania@yahoo.com

Nandita Satsangee

Professor, Dept. of Foundations of Education, Faculty of Education, Dayalbagh Educational

Institute. Agra (U.P.)

E-mail:nanditasatsangee@gmail.com
} 
in the process of school improvement has been identified by many research studies. Unlike in past where only principals and administrators were supposed to exhibit school leadership, in the modern times teachers' role as a leader is much highlighted. According to Murphy (2005), "teachers have a wider and deeper role to play; wider in extending their leadership to school wide concerns and deeper in using this school wide influence to increase teaching efficacy in the classroom".

\section{Transformational, Transactional AND LaISSEZ-FAire LEADERSHIP}

Leadership until now has been studied in many styles and forms. But in recent times transformational leadership is evolving as a more humanistic and conscious form of leadership. Over the last thirty years, transformational leadership has become one of the most prominent theories of organizational behaviour. Burns (1978) was the first author to introduce the concept of transforming (later used as transformational) leadership, and to contrast 'transforming' and 'transactional' leadership (Bass \& Riggio, 2006 as cited in Muenjohn, 2012). He defined transformational leadership as a process where leaders and followers engage in a mutual process of raising one another to higher levels of morality and motivation. He further explained that it is a process in which leaders try to raise the consciousness of followers by appealing to higher ideals and moral values.

According to Bass and Avolio (as cited in Riaz, 2012), transformational leadership comprises of four dimensions: 1. Idealised influence: It refers to leaders who encourage the followers to share their visions \& goals and to the level of trust and admiration that leaders get from their followers. 2 . Inspirational Motivation: This dimension refers to the inspiration of the followers by the leader and creating in them a future vision. 3. Intellectual Stimulation: It refers to the challenging of ideas and values of the followers by the leader for solving various problems. It is about raising their creativity to solve different problems by questioning attitudes and reframing the problem. 4. Individualised Consideration: Individualised consideration refers to the special attention given by the leader to followers based on the differences of their needs, satisfying their valid needs and elevating motivation levels.

Opposed to transformational leadership is transactional leadership, also known as managerial leadership. According to Cherry (2012), the basic assumptions of transactional leadership are: Clear and specific commands lead to performance; Motivation of workers by reward and punishment; Primary goal of the followers is to obey the instructions and commands of the leader and careful monitoring of the followers is required for achieving the set goals. It comprises of two dimensions: 1. Contingent Reward: In this dimension, good performances of the followers are rewarded and recognized, and for poor performance the leader takes the disciplinary actions. 2. 
Management by Exception: Corrective criticism, negative feedback and negative reinforcements are involved in this dimension.

According to Bass, (1985, as cited in Muenjohn, 2012) the behaviour of transformational and transactional leadership are not separated, however a leader may show a varying amount and intensity in his behaviour or both at the same time as well. The advantages of transformational leadership in school settings have been revealed by a large number of research findings. A study by Koh, Steers and Terborg (2006) has shown significant add-on effects to transactional leadership in the prediction of organizational commitment, organizational citizenship behaviour, and teacher satisfaction. An indirect effect on student academic achievement was also noticed. Horn-Turpin, (2009) revealed that as special education teachers' perceptions of administrative support increases, so do their levels of job satisfaction and organizational commitment. A significant relationship between transformational leadership and academic competence was also found. Ross and Gray (2006) discovered that Schools with higher levels of transformational leadership had higher collective teacher efficacy, greater teacher commitment to school mission, school community, and school $\square$ community partnerships, and higher student achievement also increasing the transformational leadership practices in schools makes a small but practically important contribution to overall student achievement.

\section{CONSCIOUSNESS}

No aspect of human mind is as complex, puzzling, mysterious and indefinable as is consciousness. As Baars (1997) puts it, "Consciousness seems to be the biggest and loudest phenomenon we can possibly study, as it is the study of human mind by the human mind". In its simplest form, Velman (1991) considers consciousness in everyday life as presence or absence of experiences. According to him, if phenomenal content (experience) is present, the person is conscious and if phenomenal content is absent the person is not conscious. Baars, (2003) defines the conscious processes as events that can be reported and acted upon with verifiable accuracy under optimal reporting conditions (minimum delay between event and report).

Consciousness has only recently emerged as a psychological variable and the consciousness quotient (CQ) theory and consciousness quotient inventory are latest arrivals in the theory of consciousness (Brazdau 2008, as cited in Brazdau, 2011). Brazdau (2011) defines consciousness quotient as the general level of being conscious / aware throughout a day, in regular life conditions. According to him, higher CQ implies access and processing of plenty of information where as a lower CQ means accessing and processing less information. 


\section{CONSCIOUSNESS AND LEADERSHIP}

Consciousness is the demand of modern managerial and leadership practices. Heaton and Harung (1999) advocate the need of consciousness as a foundation for organizational transformation as according to them consciousness pervades the evolving order of natural world. Hayden and Jager (2010) outline the portrait of a superior leader in new generation as one who is capable to access multiple sources of information simultaneously, who also has greater awareness and who knows how to access and operate in a more conscious way. Thus it will not be an exaggeration to say that consciousness has a vital role in organizational transformation and in effective leadership. Carter (2009) also emphasizes the role of consciousness in leadership effectiveness. According to her "Consciousness begins with the self and self awareness. Awareness flows into every part of work life and is fundamental to leadership effectiveness. Many challenges faced by the leaders in the 21st century demand profound levels of individual and collective awareness. Without this, leaders will not be able to develop the multiple levels of consciousness which they need, to have fluidity, flexibility and openness in their work."

A study of theory of leadership and consciousness gives an insight to the researcher that transformational leadership is the need of every organization and consciousness in leaders is the best sought after thing in leadership. This raises a curiosity in the mind of the researcher whether do these two share a relationship? And hence the study was undertaken.

\section{OBJECTIVES}

The study was conducted with the following objectives:

1. To study the distribution of consciousness scores of teacher trainees.

2. To study the leadership approach of teacher trainees (transformational, transactional or Laissez- Faire).

3. To study the correlation between consciousness and the seven factors of leadership.

4. To study the relationship between consciousness and various approaches of leadership.

\section{OPERATIONAL DEFINITIONS}

\section{Leadership Approach}

Leadership approach is the leadership type assessed by the various factors of MLQ-6S. Four factors i.e. idealized influence, inspirational motivation, intellectual stimulation and individualized consideration assess transformational leadership approach. Two factors i.e. contingent reward and 
management by exception assess transactional leadership approach. LaissezFaire, which is the last factor, is the third approach of leadership.

\section{Level of Consciousness}

Level of consciousness is the general level of being aware throughout the day as assessed by six dimensions of CQ-i [i.e. Physical, cognitive, emotional, spiritual, social relational and self consciousness]. It is obtained in the form of a cumulative score in all these six dimensions in the form of consciousness quotient.

\section{MeTHODOLOGY}

The study was carried out on lines of the descriptive survey method.

\section{SAMPLE}

The sample consisted of 100 teacher trainees (Male: Female ratio $=1: 1$ ) of a selffinanced college of education from Agra district.

\section{TOOLS USED}

\section{Leadership Approach}

The Multi-factor Leadership Questionnaire (MLQ-6S) developed by Bass and Avolio (1992), which is a standardized tool, was used to assess the leadership style. The MLQ-6S measures a broad range of leadership types/approaches from passive leaders (Laissez faire), to leaders who give contingent rewards to followers (Transactional), to leaders who transform their followers into becoming leaders themselves (Transformational). MLQ is valid across cultures, different organizational types and leadership levels. The tool is a five point likert scale consisting of twenty one items. It measures leadership on seven factors. The score of each factor is determined by adding three specified items on the questionnaire. The factors are Idealized Influence, Inspirational motivation, Intellectual stimulation, Individualized consideration, Contingent reward, Management-by-exception which are already discussed above. Seventh factor is 'Laissez-faire leadership' which refers to letting others do their own thing.

\section{Consciousness Quotient Inventory}

To measure the Consciousness Quotient, a standardized tool i.e. Consciousness Quotient Inventory (CQ-i) developed by Brazdau (2011) was employed. CQ-i is composed of six dimensions: Physical (8 items), Emotional (10 items), Mental (9 items), Spiritual (13 items), Social-relational ( 9 items) and Self (13 items). CQ-i has 62 items scored with a 5 point likert scale from strongly disagree to strongly agree. It measures six primary factors and nine secondary 
factors. The primary six factors of the Consciousness Quotient refers to the following aspects: (1) Physical Consciousness: refers to the ability of being conscious of the body and organism, and of the physical elements of the environment (8 items); (2) Emotional Consciousness: describes the ability of being conscious of your own emotions and feelings, and generally, to be conscious of any emotional feeling (10 items); (3) Mental (Cognitive) Consciousness: refers to the ability of being conscious of your own ideas, of the mental stream generally (9 items); (4) Spiritual Consciousness: refers to the ability of being conscious about yourself as a part of the universe, and describes the ability of being conscious about the multiple connections with the surrounding life (13 items); (5) Social - Relational Consciousness: refers to the ability of being conscious about human relationships and the connections with the people you interact with (9 items); (6) Self-Consciousness: Consciousness of Self or Self-Awareness refers to the ability of being conscious about your own person, your own self; this factor describes the ability of the reflexivity of the human being, of being able to look upon itself in an objective way (13 items). CQ-i also measures 9 secondary factors which are (1) Internal State Awareness: refers to the ability of being conscious specifically about the inner changes; (2) Self-Reflectiveness: refers to the ability of being conscious in a reflective way about your own person; (3) Mindfulness: refers to a way of looking at yourself and your environment in a non-judgmental way; (4) Autonomy: refers to the degree of autonomy- the individualization of a person; in other words, the ability to function autonomous, without requiring external support; (5) Personal Growth: refers to the ability of being conscious about the evolutionary transformation one person goes through; (6) Positive Relations with Others: is the ability of being conscious about inter-personal relationships; (7) Purpose in Life: refers to existence of a purpose in life. Purpose is the context of meaning within which one makes life choices; (8) Verbal Expression: describes the ability of expressing the conscious content through verbal communication; (9) Openness towards new experiences: refers to the ability of being conscious about new information; generally it is the ability of being open to any new things happening around oneself.

The inventory is having a high internal consistency, that is, Chronbach Alpha $=0.92$ for $\mathrm{N}=62$ and high construct as well as concurrent validity.

\section{ANALYSIS AND RESUlts}

Upon analysis of distribution of consciousness scores of teacher trainees, it was found that scores of consciousness approached nearly the normal distribution. The leadership scores also followed a trend that was close to normal distribution. Based on the norms, 35\% students scored high, 39\% scored moderate whereas only $1 \%$ scored low on MLQ. The factor-wise distribution is presented in Table 1. 
255 | Vaibhav Chauhan, Sadhna Sharma and Nandita Satsangee

Table 1

Factor Wise Analysis of Range of Scores.

\begin{tabular}{|l|c|c|c|}
\hline & High (\%) & Moderate (\%) & Low (\%) \\
\hline $\begin{array}{l}\text { Idealized Influence } \\
\text { (I.I) }\end{array}$ & 56 & 39 & 5 \\
\hline $\begin{array}{l}\text { Inspirational } \\
\text { Motivation (I.M) }\end{array}$ & 59 & 37 & 3 \\
\hline $\begin{array}{l}\text { Intellectual } \\
\text { Stimulation (I.S) }\end{array}$ & 41 & 56 & 4 \\
\hline $\begin{array}{l}\text { Individualized } \\
\text { Consideration (I.C) }\end{array}$ & 42 & 42 & 14 \\
\hline $\begin{array}{l}\text { Contingent Reward } \\
\text { (C.R) }\end{array}$ & 44 & 41. & 6 \\
\hline $\begin{array}{l}\text { Management-by- } \\
\text { exception (M.E) }\end{array}$ & 53 & 58 & 11 \\
\hline Laissez Faire (L.F) & 31 & 54 & \\
\hline
\end{tabular}

It is evident from Table 1 that most of the students scored high on the dimensions of idealized influence, inspirational motivation, contingent reward and management by exception and in rest of the dimensions, most of students scored moderately. It can also be seen that highest number of low scoring students were found in Laissez-Faire leadership. The factor of inspirational motivation was most favoured whereas factor of contingent reward and laissez-faire were most unfavoured.

Table 2

Mean and Standard Deviation of Consciousness Scores and Transformational Leadership Scores of Teacher Trainees.

\begin{tabular}{|c|c|c|c|c|c|c|c|c|c|}
\hline & $\begin{array}{c}\text { Consciousness } \\
\text { Scores }\end{array}$ & \multicolumn{9}{|c|}{ Leadership Scores (For 7 factors) } & $\begin{array}{c}\text { Overall } \\
\text { Leadership } \\
\text { Score }\end{array}$ \\
\hline & & (I.I) & (I.M) & (I.S) & (I.C) & (C.R) & (M.E) & (L.F) & All factors \\
\hline Mean & 266.35 & 8.65 & 8.66 & 8.02 & 8.5 & 7.93 & 8.43 & 7.21 & 57.54 \\
\hline SD & 22.56 & 2.28 & 1.94 & 1.90 & 2.06 & 2.78 & 2.39 & 2.17 & 9.69 \\
\hline Skewness & -0.242 & \multicolumn{10}{|c|}{-0.465} \\
\hline Kurtosis & -0.133 & \multicolumn{10}{|c|}{-0.318} \\
\hline
\end{tabular}

The scores for leadership were more skewed and were having high kurtosis as compared to distribution of scores for consciousness. However the values of both skewness and kurtosis are found to be not significant. 
The correlation between seven factors of MLQ and consciousness was calculated using Pearson's product moment correlation. Results are presented in Table 3.

Table 3

Correlation Between Consciousness Scores and Seven Factors of Leadership Approach.

\begin{tabular}{|l|c|}
\hline \multicolumn{1}{|c|}{ Factors of MLQ } & Correlation with Consciousness \\
\hline Idealized Influence & $0.30^{*}$ \\
\hline Inspirational Motivation & $0.22^{* *}$ \\
\hline Intellectual Stimulation & $0.23^{* *}$ \\
\hline Individualized Consideration & $0.38^{*}$ \\
\hline Contingent Reward & 0.15 \\
\hline Management by Exception & $0.34^{*}$ \\
\hline Laissez faire & $0.21^{* *}$ \\
\hline Overall & $0.41^{* *}$ \\
\hline
\end{tabular}

${ }^{*} p<0.01,{ }^{* *} p<0.05$

It is evident from the correlation values that a significant positive and moderate correlation was found between leadership and consciousness scores. Separate analysis of each factor indicated that idealized influence and individualized considerations were significantly correlated with consciousness and that too with highest magnitude among all other factors. Factor of contingent reward was found to be not significantly correlated with consciousness.

Correlation of each type of leadership approach with consciousness was calculated and the results are presented in Table 4.

\section{Table 4}

Correlation of Consciousness with Transformational, Transactional and Laissez-Faire Approaches of Leadership.

\begin{tabular}{cccc}
\hline $\begin{array}{c}\text { Leadership } \\
\text { Approach }\end{array}$ & Transformational & Transactional & $\begin{array}{c}\text { Laissez- } \\
\text { Faire }\end{array}$ \\
\hline $\begin{array}{c}\text { Correlation with } \\
\text { Consciousness }\end{array}$ & $0.443^{*}$ & $0.321^{*}$ & $0.214^{* *}$ \\
\hline
\end{tabular}

${ }^{*} p<0.01,{ }^{* *} p<0.05$

Form Table 4 it can be seen that transformational leadership approach was positively, moderately and significantly correlated with level of consciousness followed by transactional (moderate correlation) and laissez-faire approach 
(low correlation) respectively as indicated in Figure 1.

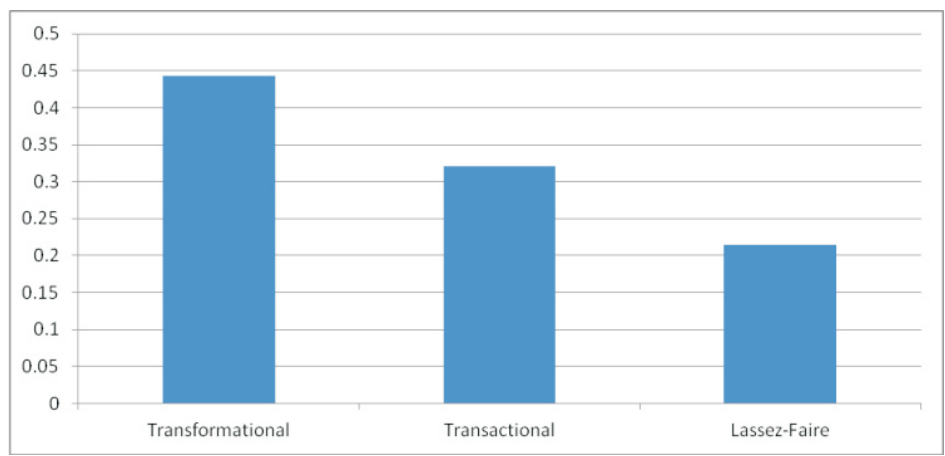

Figure 1. A Comparison of Correlation of Three Leadership Approaches with Consciousness

\section{DISCUSSION OF RESULTS}

It was found that most of the teacher trainees have average level of consciousness and as a leader most of them have transformational leadership approach. The results indicate that there is a positive relationship between approach of leadership and consciousness of leaders i.e. with the rise in the level of consciousness, there is a transition in one's approach from Laissez-faire to transformational via transactional. Interestingly, highest correlation of transformational leadership approach is with consciousness, followed by transactional and laissez-faire approach. This indicates transition in the leadership approach in the same order for a given rise in consciousness. It can also be interpreted from the study that a less conscious leader will let the followers have their own way, which may create chaos and downfall of the institution in the long run. It can be assumed provisionally that transformational approach of a conscious leader may be ascribed to his consciousness in various dimensions. Perhaps, his emotional consciousness makes him conscious and efficient towards holding subordinates' trust, and maintaining their faith and respect. His cognitive consciousness may prove as an asset in providing future vision and focus to followers, and most importantly in stimulating the followers intellectually, facilitating their creativity and novelty. Through his spiritual consciousness, he may make them more aware about their values and beliefs and how they comply with values and beliefs of their organization. He may also develop a critical sense in them whether these values and beliefs are appropriate to achieve both long term and short term goals of the organization and institution. The social and relational consciousness of a leader may make him much aware about human relations and well being, needs and requirements of every individual. Bass and Riggio (as cited in Muenjohn, 2007) have also mentioned that a transformational 
leader also raises the awareness of employees and in the long run they transform their followers into leaders themselves. However, further studies enquiring the relationship between each dimension of consciousness with the factors of transformational leadership may contribute significantly in proving these assumptions.

\section{CONCLUSION}

It can be concluded from the study that to have transformational leaders and leadership, consciousness as a personal construct and quality is must. A component of consciousness in teacher education is an indispensable need of the present moment. Content of such an education may involve introduction to the concept of consciousness and behavioural practices that enhance awareness about one's own self as well as towards other human beings, including human relations and the environment in which they are nurtured.

People who are already working as a leader at some or the other position such as teachers, principals and educators may work upon developing focus, desire and attitude for enhancing their consciousness. According to Beer (n.d.), as a conscious leader, they must be able to work with even those perspectives which differ from theirs. He suggests that they may work upon: 1. Awareness of one's own emotions and sentiments to overcome stress and anxiety. 2. Encouragement of people to give honest feedback regularly and avoiding defence mechanisms while receiving it. 3. Learning about psychological diversities or preferences, shadows, strengths and weaknesses. 4. Learning inclusive leadership skills such as listening, situational leadership, coaching, giving and receiving feedback and team leadership and learning to reflect as an individual and as a team.

A large part of consciousness and leadership may come by the virtue of birth but the assumption that 'human behaviour is modifiable' gives a silver lining to the entire aspect.

\section{REFERENCES}

Baars, B.J. (1997). In the theatre of Consciousness: The workspace of mind. Retrieved from http://bernardbaars.pbworks.com/f/Baars \%20Theater \% 20 book $\% 20 \mathrm{Ch} \% 201-2$.pdf.

Baars, B.J. (2003). Introduction: Treating Consciousness as a variable: The fading taboo. Retrieved from http://www.upaya.org/ uploads/pdfs / Baars2003.pdf.

Bass, B., \& Avolio, B. (1992). Transformational Leadership. In Leadership, (pp. 131159). Retrieved from http://kcxt.cdu.edu.cn /eol/common/ fckeditor /openfile.jsp?id=.

Bass, B.M. (1999). Two decades of Research and development in Transformational 
Leadership. Retrieved from http://www.techtied.net/wp-content/ uploads/2007/10/bass_transforrmational_leadership.pdf.

Beer, P.D (n.d.). Conscious leader as a key factor of sustainability. Retrieved from http://www.villageofleaders.co.za/conscious-leadership-a-keyfactor-of-sustainability-by-paul-de-beer/.

Brazdau, O., \& Mihai, C. (2011). The Consciousness quotient: a new predictor of students academic performance. Procedia Social and Behavioural Sciences, 11, 245-250.

Brazdau, O. (2013). What is CQ? Retrieved from http:/ /www.consciousnessquotient.com/what-is-cq.

Burns, J.M. (1978).Transformational Leadership Theory. Retrieved from http:/ / www.leadership-central.com/burns-transformationalleadership-theory.html\#axzz 2Naz97Re4.

Carter, H. (2009). What do we mean by conscious leadership? Retrieved from http:/ / neelabettridge.co.uk/wp-content/uploads / 2013/03/cclmodelexecsummary 12-august-09.pdf.

Cherry, K. (2012). What is transactional Leadership? Retrieved from http:// psychology.about.com/od/leadership/f/transactionalleadership.htm.

Heaton, D.P., \& Harung, H.S. (1999) "The Conscious Organization". The Learning Organization, 6(4), 157-163. Retrieved from http:/ / www.emeraldinsight.com /journals.htm?articleid $=882576$.

Hayden, G., \& Jager, K.D. (2010). Demystifying the consciousness quotient. Retrieved from http://www.sphereconsulting.org/newtrends/Demystifying\%20the \% 20 Consciousness \% 20Quotient.pdf.

Horn-Turpin, F.D. (2009). A Study Examining the Effects of Transformational Leadership Behaviours on the Factors of Teaching Efficacy, Job Satisfaction and Organizational commitment as Perceived by Special Education Teachers. Retrieved from http://scholar.lib.vt.edu/theses / available/etd-02152009-080918/ unrestricted/ FDHornTurpinETD09.pdf.

Koh, W.L., Steers, R.M., \& Terberg, J.R. (2006). The effects of transactional leadership on teacher attitudes and student performance in Singapore. Retrieved from http://onlinelibrary.wiley.com/doi /10.1002/job.4030160404/abstract.

Mourshed, M., \& Barber, M. (2010). How the world's most improved school systems keep getting better. Retrieved fromwww.mckinsey.com /client_service/social_sector/latest_thinking/worlds_most_impr oved_schools.

Muenjohan, N. (2007). Transformational Leadership: A new force in leadership research. Retrieved from http://www.wbiconpro.com/436Nuttawuth.pdf.

Murphy. (2005). Connecting teacher leadership and school improvement. The Educational Forum, 68, 276-286. Corwin Press, Thousand Oaks, CA. 
Riaz, O. (2012). Spirituality \& Transformational Leadership in Education. Retrieved from http://digitalcommons.fiu.edu/cgi/viewcontent .cgi? article $=1763 \&$ context $=$ etd.

Ross, J.A., \& Gray, P. (2006). School Leadership and Student Achievement: The Mediating Effects of Teacher Beliefs. Canadian Journal of Education, 29 (3), 798-822. Retrieved from http://www.cssescee.ca/CJE/Articles/FullText/CJE29-3/ CJE29-3Ross\%26Gray.pdf.

Velman, M. (2009). How to define consciousness and how not to define consciousness. Journal of Consciousness Studies, 16(5), 139-156. 